\title{
Environmental change across the PETM- New evidence from Alamedilla (S Spain)
}

\author{
A.Molero-MONSONÍS ${ }^{1}$, J.M.CASTRO ${ }^{2 *}$, \\ M.L.QUIJANO ${ }^{2}$, G.DE GEA ${ }^{2}$, M. RODRIGO- \\ GÁMIZ ${ }^{3}$ AND L.ALEGRET ${ }^{4}$
}

${ }^{1}$ Universidad Complutense de Madrid, 28040 Madrid, Spain

${ }^{2}$ CEACTEMA, Universidad de Jaén, 23071 Jaén, Spain

(*correspondence: jmcastro@ujaen.es)

${ }^{3}$ Universidad de Granada, 18071 Granada, Spain

${ }^{4}$ Universidad de Zaragoza,50009 Zaragoza, Spain

\section{Introduction}

The Paleocene-Eocene Thermal Maximum (PETM) is a global hyperthermal event considered as an analogue to the current anthropogenic climate change. It is recorded with a negative carbon isotope excursion (CIE) related to a huge release of light carbon to the ocean-atmosphere system. Rapid global warming and changes in the geochemistry of the oceans eventually led to changes in marine and terrestrial biota [1]. We have investigated the Paleocene-Eocene transition in a deep pelagic succession at Alamedilla (southern Spain), where the benthic foraminiferal turnover across the PETM has been previously documented [2].

\section{Multiproxy geochemical study}

We provide new data from the Alamedilla section, combining for the first-time trace element distributions, carbon and oxygen stable isotopes, total organic carbon content, and selected biomarkers. Biomarkers are mainly dominated by $n$-alkanes, hopanes and steranes, and minor abundances of acyclic isoprenoids, and GDGTs. Trace element ratios have been diagnostic for palaeoredox conditions, terrestrial inputs, and primary productivity.

Discussion

These data allowed us to distinguish four phases across the PETM record, which are consistent with those proposed by Alegret et al. [2] based on benthic foraminifera: (1) Preextinction phase (pre-CIE), with some changes in biomarkers. (2) Extinction phase coeval with the onset of CIE, marked by low continental input and productivity. (3) Survival phase (end of CIE and following positive trend), with an increase in organic terrestrial inputs and elemental productivity markers, and finally the (4) recovery phase, postdating the CIE characterized by general low productivity and terrestrial input.

[1] Penman \& Zachos (2018) Environ. Res. Lett. 13.

[2] Alegret et al. (2009) Palaeogeogr. Palaeoclimatol. Palaeoecol. 279, 186-200. 